Mihaela Brumen, Tomaž Zupanči

Slovenia

María Fernández Agüero, Isabel Alonso-Belmôn

Spain

\title{
Foreign Language Teachers' Feedback Practices: a Comparative Study
}

DOI: 10.15804/tner.2018.53.3.18

\begin{abstract}
The purpose of this study is to describe the current foreign language (FL) assessment and feedback practices as reported by 213 experienced primary teachers in Slovenia and Spain. An ad hoc questionnaire was designed, validated and administered to 113 Slovenian and 100 Spanish teachers. The data were collected and analysed with the use of descriptive and inferential statistics. Among the most relevant findings, it is noteworthy that Spanish teachers focus on providing feedback on receptive skills while their Slovenian colleagues pay more attention to productive skills. Also, results from both groups reveal a lack of FL pronunciation feedback and scarce attention to interactive aspects of communication.
\end{abstract}

Keywords: assessment, feedback comments, foreign language, teacher education, young learners.

\section{Introduction}

This paper's main aim is to explore Spanish and Slovenian foreign language (FL) teachers' reported feedback practices when assessing the four skills in the primary classroom. Feedback is the "information that is given to the learner about his or her performance of a learning task, usually with the objective of improving this performance" (Ur, 1996, p. 242), composed of assessment, informing about the 
overall quality of performance, and correction, giving details on particular aspects of the performance.

This information can be either oral or written, positive or negative, explicit or implicit, and has a powerful but variable influence on FL learning by giving learners the opportunity to enhance their metalinguistic awareness (Swain, 1995) and to modify their output (Bitchener, Young \& Cameron, 2005; Farrokhi, 2012; Khatri, 2013). Giving effective feedback at appropriate points in time is thus a fundamental feature of good teaching practice.

In the classroom, feedback can serve to diagnose strengths and weaknesses in the skills being taught in order to make positive changes in students' learning, thus carrying out diagnostic formative assessment (Jang \& Wagner, 2014). Indeed, assessment builds a picture of young learners' (YLs) progress over time. The FL teacher uses this information in order to choose the most appropriate assessment methods in the interest of the YL, and to reflect and improve the FL teaching and learning process. Research also points out (McKay, 2006) that young FL learners' assessment should be performed in a stress-free environment, including communicative, all-inclusive assessment activities oriented to the age and interest of children, helping YLs to perceive assessment as part of communication, and not a competitive grading activity.

\section{The presented research project}

\section{Methodology}

Our research is based on the descriptive and causal-non-experimental methods of empirical pedagogical research. The data were collected from a non-random sample of 213 FL teachers - 113 from Slovenia and 100 from Spain, working in the region of Madrid. As a measuring tool for the empirical research, a questionnaire was designed focusing on assessment in relation to language skills. The questionnaire was furnished with the following characteristics (Fraenkel, Wallen \& Hyun, 2014): validity (conducted on the basis of scientific literature), including a pilot study; reliability (exact instructions and clear, specific questions); and objectivity (closed-type questions). The Cronbach coefficient $(\alpha=0.916)$ confirmed the high reliability of the instrument.

As for the procedure followed, an online version of the questionnaire was sent to all primary school head teachers in Slovenia (420 state primary schools) and to the head teachers of the primary schools database of Universidad Autónoma de Madrid in the region of Madrid (200 primary schools, state and private but state 
funded). At our request, they forwarded the questionnaires to their colleagues, FL teachers (of English and other languages), who completed it online. In Slovenia, the questionnaire was also filled in at an in-service teacher training course. In Spain, it was also sent to individual FL teachers (working in bilingual and monolingual schools), who completed it online. The data were analysed with the use of descriptive and inferential statistics (f, f\%, , Mann-Whitney U test).

To calculate the figures on feedback comments for each individual language skill, we grouped these items in the questionnaire dealing with the assessment of each skill (4-5 items per skill, as shown below), estimated the average values of answers to these items and then their mean values.

\section{Participants}

The study involved 213 teachers who teach FLs to YLs from 6 to 12 years of age. The average age of the FL teachers (37.23 in Slovenia, 38.33 in Spain), their gender (92.03\% of females in Slovenia; $87.00 \%$ in Spain) and the work period (no statistically significant differences) are similar in both countries. Besides, in our sample, $34.13 \%$ of the Slovenian teachers are generalists and $56.87 \%$ are specialists. Concerning Spain, 78\% of the teachers were trained as FL specialists who work either in the private sector or in the public sector, where they had to take a comprehensive exam in FL teaching. The remaining $22 \%$ who claim to be generalists have become FL teachers by taking this exam.

\section{Results}

\section{General reported feedback practice on the four skills}

Results show that the Spanish and Slovenian FL teachers report similar feedback practices. The four skills are assessed proportionally in the FL primary classroom, as can be seen in Table 1, although the general tendency is to focus on reading more frequently than on the other language skills $(\bar{x}=4.010)$. Answers on the remaining three language skills (listening, writing, speaking) are very similar.

Table 1. Feedback and comments provided when assessing the four languages skills

\begin{tabular}{|c|c|c|c|c|c|c|c|c|}
\hline \multirow{2}{*}{ Assessing } & \multicolumn{2}{|c|}{$\Sigma$} & \multirow{2}{*}{ country } & \multirow{2}{*}{$\bar{x}$} & \multirow{2}{*}{ rank } & \multirow{2}{*}{$\bar{R}$} & \multicolumn{2}{|c|}{ Mann-Whitney U } \\
\hline & $\bar{x}$ & rank & & & & & $\mathrm{U}$ & $P$ \\
\hline \multirow[t]{2}{*}{ Reading } & 4.010 & 1 & SLO & 3.84 & 3 & 95.53 & 4353.5 & 0.003 \\
\hline & & & SPA & 4.19 & 1 & 119.97 & & \\
\hline
\end{tabular}




\begin{tabular}{|c|c|c|c|c|c|c|c|c|}
\hline \multirow{2}{*}{ Assessing } & \multicolumn{2}{|c|}{$\Sigma$} & \multirow{2}{*}{ country } & \multirow{2}{*}{$\bar{x}$} & \multirow{2}{*}{ rank } & \multirow{2}{*}{$\bar{R}$} & \multicolumn{2}{|c|}{ Mann-Whitney U } \\
\hline & $\bar{x}$ & rank & & & & & $\mathrm{U}$ & $P$ \\
\hline \multirow[t]{2}{*}{ Listening } & 3.944 & 2 & SLO & 3.80 & 4 & 95.50 & 4350.0 & 0.003 \\
\hline & & & SPA & 4.09 & 2 & 120.00 & & \\
\hline \multirow[t]{2}{*}{ Writing } & 3.937 & 3 & SLO & 3.87 & 1 & 105.38 & 5466.0 & 0.680 \\
\hline & & & SPA & 4.01 & 4 & 108.84 & & \\
\hline \multirow[t]{2}{*}{ Speaking } & 3.935 & 4 & SLO & 3.85 & 2 & 99.96 & 7855.0 & 0.074 \\
\hline & & & SPA & 4.03 & 3 & 114.95 & & \\
\hline
\end{tabular}

A closer look reveals some transnational differences. While the Spanish FL teachers provide more frequent feedback comments on reading (4.19), followed by listening, speaking and writing, in this order, the Slovenian teachers concentrate more on assessing writing (3.87), and then on speaking, reading and listening. However, there are statistically significant differences between the countries, except in the productive skills (writing and speaking). If anything, the mean values $(\bar{x})$ of the Slovenians indicate that they ranked their answers lower than their Spanish colleagues.

\section{Providing feedback on listening}

Table 2 presents the issues that are corrected more often when assessing YL's listening performance.

Table 2. Feedback and comments FL teachers provide by assessing listening

\begin{tabular}{lccccc}
\hline \multicolumn{1}{c}{\begin{tabular}{c} 
By assessing listening, I provide \\
\multicolumn{1}{c}{ feedback and comments on: }
\end{tabular}} & country & $\bar{x}$ & $\bar{R}$ & \multicolumn{2}{c}{$\begin{array}{c}\text { Mann-Whitney U } \\
\text { U P }\end{array}$} \\
\hline recognizing the phonemes, rhythms and & SLO & 3.19 & 98.97 & 4743.0 & 0.036 \\
patterns & SPA & 3.52 & 116.07 & & \\
\hline understanding and following simple oral & SLO & 3.99 & 95.06 & 4301.0 & 0.001 \\
messages in context & SPA & 4.33 & 120.49 & & \\
\hline identifying simple details in oral texts (e.g., & SLO & 3.93 & 100.06 & 4865.5 & 0.057 \\
colours) & SPA & 4.17 & 114.85 & & \\
\hline comprehending the overall sense of texts & SLO & 4.11 & 97.32 & 4556.0 & 0.008 \\
(e.g., stories) & SPA & 4.37 & 117.94 & & \\
\hline
\end{tabular}

Clearly, assessing comprehension of the overall sense of texts (e.g., stories) is important for the FL teachers in both groups since they provide their YLs with very frequent feedback on this. On the other hand, detailed listening comprehen- 
sion - such as understanding and following simple oral messages in context and identifying simple details in oral texts - draw less attention, and the least attention is paid to providing feedback on recognising pronunciation.

There are statistically significant differences between Slovenia and Spain in all four items: again, the mean values $(\bar{x})$ show that the Slovenian FL teachers ranked their answers lower than their Spanish counterparts. This might indicate that they do not provide feedback and assess YLs' listening skills as often, or that there is a consistent tendency for the Slovenian teachers to choose medium values of responses (e.g., 'very often' rather than 'always'). Nevertheless, the pattern of responses to the different items in both countries is similar, except that the Slovenians seem to be more conservative in their ratings.

\section{Providing feedback on reading}

In Table 3 we present the components of reading that these teachers tend to focus upon more when giving feedback to YLs.

Table 3. Feedback and comments FL teachers provide by assessing reading

\begin{tabular}{|c|c|c|c|c|c|}
\hline \multirow{2}{*}{$\begin{array}{l}\text { By assessing reading, I provide } \\
\text { feedback and comments on: }\end{array}$} & \multirow{2}{*}{ country } & \multirow{2}{*}{$\bar{x}$} & \multirow{2}{*}{$\bar{R}$} & \multicolumn{2}{|c|}{ Mann-Whitney U } \\
\hline & & & & $\mathrm{U}$ & $\mathrm{P}$ \\
\hline \multirow{2}{*}{$\begin{array}{l}\text { understanding and following written messages } \\
\text { at the word/sentence level }\end{array}$} & SLO & 3.87 & 99.36 & 4786.5 & 0.035 \\
\hline & SPA & 4.16 & 115.64 & & \\
\hline \multirow{2}{*}{$\begin{array}{l}\text { understanding the overall sense of short writ- } \\
\text { ten texts (e.g., true/false) }\end{array}$} & SLO & 3.97 & 95.96 & 4402.0 & 0.002 \\
\hline & SPA & 4.34 & 119.48 & & \\
\hline \multirow{2}{*}{$\begin{array}{l}\text { extracting specific information from brief } \\
\text { texts (e.g., familiar topics, finding the correct } \\
\text { picture/character, reading and drawing) }\end{array}$} & SLO & 3.79 & 96.07 & 4415.0 & 0.003 \\
\hline & SPA & 4.16 & 119.35 & & \\
\hline \multirow{2}{*}{$\begin{array}{l}\text { understanding and following brief written } \\
\text { messages (e.g., matching questions to the } \\
\text { answers, putting short paragraphs in the right } \\
\text { order) }\end{array}$} & SLO & 3.73 & 95.47 & 4347.0 & 0.002 \\
\hline & SPA & 4.13 & 120.03 & & \\
\hline
\end{tabular}

According to the results in Table 3, the FL teachers in the survey provide feedback on their students' understanding of the overall sense of short written texts (e.g., true/false) and of written messages at the word/sentence level the most frequently. Then, they provide feedback and comments on extracting specific information from brief texts, and on understanding and following brief written messages. It seems, then, that the teachers place emphasis on general understanding as opposed to reading for detail. 
Concerning the comparison between the Slovenians and Spaniards, once more, the data yield statistically significant differences in all the four items. Again, as evident in the mean values $(\overline{\mathrm{x}})$, the Slovenian FL teachers ranked their importance lower than their Spanish colleagues.

\section{Providing feedback on speaking}

Turning to productive skills, Table 4 shows what aspects of speaking are focused upon more.

Table 4. Feedback and comments FL teachers provide by assessing speaking

\begin{tabular}{llcccc}
\hline \multicolumn{1}{c}{$\begin{array}{c}\text { By assessing speaking, I provide } \\
\text { feedback and comments on: }\end{array}$} & Country & $\overline{\boldsymbol{x}}$ & $\overline{\boldsymbol{R}}$ & \multicolumn{2}{c}{ Mann-Whitney U } \\
\cline { 3 - 6 } & & & & $\mathrm{U}$ & $\mathrm{P}$ \\
\hline fluency (e.g., interactive communication, & SLO & 4.11 & 105.16 & 5442.5 & 0.606 \\
production of short, modelled or original & SPA & 4.19 & 109.08 & & \\
oral messages) & & & & & \\
\hline pronunciation, stress and rhythm & SLO & 3.72 & 100.19 & 4880.0 & 0.068 \\
& SPA & 4.01 & 114.70 & & \\
\hline accuracy (e.g., vocabulary and grammar) & SLO & 3.88 & 100.76 & 4945.0 & 0.086 \\
& SPA & 4.08 & 114.05 & & \\
\hline discourse management (e.g., initiation of & SLO & 3.61 & 99.65 & 4819.0 & 0.049 \\
interaction, responding, clear idea develop- & SPA & 3.85 & 115.31 & & \\
ment) & & & & & \\
\hline
\end{tabular}

Fluency and accuracy seem to be the issues that the FL teachers most frequently provide feedback and comments on. Pronunciation, stress and rhythm are next, and discourse management and interactional issues come last.

As for the contrast between the two groups of teachers, there are no statistically significant differences, except in the item concerning discourse management $(\mathrm{P}=0.049)$, which the Slovenian FL teachers ranked lower than their Spanish colleagues.

\section{Providing feedback on writing}

Finally, Table 5 reflects the importance attached to the different aspects involved in the assessment of writing.

It is evident from Table 5 that the FL teachers in both countries provide very frequent feedback on YLs' content, words and phrases. Then comes grammar, cohesion, coherence and unity. The results indicate that they give feedback on the content more than on the form, or the way to express that content; besides, the overall structure of the text - cohesion and coherence - tends to be disregarded. 
Table 5. Feedback and comments FL teachers provide by assessing written assignments

\begin{tabular}{lccccc}
\hline $\begin{array}{c}\text { By assessing written assignments, } \\
\text { I provide feedback and comments on: }\end{array}$ & Country & $\bar{x}$ & & \multicolumn{2}{c}{ Mann-Whitney U } \\
\cline { 5 - 6 } content & & & & $\mathrm{U}$ & $\mathrm{P}$ \\
& SLO & 4.15 & 112.15 & 5068.5 & 0.164 \\
& SPA & 4.08 & 101.19 & & \\
\hline textual structure and cohesion & SLO & 3.74 & 106.37 & 5578.5 & 0.868 \\
& SPA & 3.80 & 107.72 & & \\
\hline coherence and unity & SLO & 3.64 & 103.97 & 5308.0 & 0.426 \\
& SPA & 3.79 & 110.42 & & \\
\hline grammar & SLO & 3.83 & 102.35 & 5124.5 & 0.211 \\
& SPA & 4.12 & 112.26 & & \\
\hline words and phrases & SLO & 3.99 & 101.32 & 5008.0 & 0.121 \\
& SPA & 4.26 & 113.42 & & \\
\hline
\end{tabular}

There are no statistically significant differences between Slovenia and Spain in all the five items on writing. In this sense, this skill departs from the other skills (listening, speaking, and reading), where the data yielded deviations in favour of higher ranking by the Spanish teachers, statistically significant in the three cases (cf., Tables 2, 3 and 4); apparently, in providing feedback and comments on YLs' written assignments, the Slovenian teachers feel the most competent. Among all the responses, only in assessing the written assignments did we register higher mean values for the Slovenian teachers $(=4.15)$, compared with the Spanish ones $(\overline{\mathrm{x}}=4.08)$.

\section{Discussion}

The questionnaires provide interesting insights into these FL teachers' reported feedback practices in the primary classroom concerning their preferences. For example, some significant differences arise from a transnational analysis. Results show that the Spanish FL teachers tend to concentrate their feedback on receptive skills (namely, reading and listening), followed by speaking and writing, and their Slovenian colleagues give more feedback on productive skills (particularly on writing). Several reasons could explain these findings. For the Spanish teachers, especially for those working in CLIL contexts, general understanding of spoken and written FL texts is a fundamental skill for their teaching practice: their learners 
have limited exposure to the FL outside the classroom but they still need to follow complex instructions and read formal texts conveying subject matter. For these teachers, providing feedback on receptive skills seems important as it is linked to their learning goals, which could be considered a sign of good practice (Stobart, 2006).

The second reason for the prevalence of feedback on receptive skills among the Spanish teachers could be that learning to read in English is particularly problematic for Spanish students (Harris \& Hatano, 1999) because in English there is no one-to-one correspondence between sounds and graphemes, as in Spanish. By providing feedback, reading and pronunciation difficulties can be diminished.

The Slovenian teachers, on the other hand, are much more focused on productive skills and particularly on writing. There is also an explanation for this. In recent years, the comparative results of the Slovenian national FL examination (National Examination Centre, 2016), which takes place at the end of the third cycle of primary school (15 years of age), have brought to light that Slovenian YLs were slightly weaker in written assignments than in listening, speaking and reading skills. Especially challenging for the students was writing longer, creative texts. As a result, FL teachers were given general recommendations and organised workshops on how to pay attention to guided, creative writing. In the last two years, the results of national examinations in English have revealed a positive trend in the development of writing skills, as the marks have been considerably higher. Our results could be a corollary to the fact that Slovenian FL teachers have increased their awareness on the importance of developing literacy skills (National Examination Centre, 2016).

In both cases, the studied FL teachers say that they provide explicit feedback on the different aspects involved in teaching language skills (e.g., they provide feedback on interactive communication, production of short, modelled or original oral messages, on identifying and correcting words or phrases, understanding and applying grammatical rules). This could be considered an example of good practice, as giving explicit direct feedback seems an effective strategy for language development and cognitive engagement (Ferris, 2002; Seedhouse, 2001).

As for the remaining data, results point to similar reported feedback practices by both the Spanish and Slovenian FL teachers. Interestingly, feedback on the subskills is provided proportionally, in two social contexts where FLs receive dissimilar treatment (i.e., the Slovenian population is generally more proficient in FLs); and regulations reflect distinct approaches towards assessment - Slovenian assessment policy being much more explicit on how to assess. If anything, there could be a tendency for Slovenian teachers to choose the medium values of 
responses (e.g., (very) often) in the questionnaire, i.e., to be more conservative in their ratings. Further studies that dig into the possible influence of these contextual variables on feedback delivery will shed new light on effective feedback and assessment practices. As K. Hyland and F. Hyland (2006) state, feedback practices are mediated by the institutions and cultures where teachers work.

Our data also highlight areas for improvement. For example, the teachers' reported practice shows lack of FL pronunciation feedback in both countries. This is confirmed by previous investigations. For example, Derwing and Munro (2005, p. 379) state that "the study of pronunciation has been marginalised [...] as a result, teachers are often left to rely on their own intuitions with little direction." Also, in his review of studies on teachers' attitudes to pronunciation teaching, Pardo (2004) concludes that many teachers are unsure of the effectiveness of pronunciation for intelligibility and communication. Others remain sceptical about the teachability of pronunciation, and in consequence attach relatively little importance to explicit pronunciation instruction in their practice, but research suggests (Adams, Foorman, Lundberg \& Beeler, 1998) that YLs do not acquire phonemic awareness spontaneously. Therefore, FL teachers should pay more attention to providing feedback to FL sounds and rhythms.

Finally, both groups of teachers, the Slovenians in particular, fail to provide feedback on discourse management (e.g., to encourage YLs to ask questions, to initiate interaction, develop clear ideas, etc.). This brings out scarce attention paid to discourse-based teaching and assessment, using authentic, pragmatic (written) and spoken FL discourse in primary education settings (Celce-Murcia \& Olshtain, 2000), and coincides with previous research on the lack of feedback on the interactional aspects of productive skills in the FL classroom (Sert, 2015; Walsh, 2011). In our data, fluency and accuracy are constantly paid attention to, in detriment of other subskills such as the ability to negotiate and construct meanings with another interlocutor. In particular, feedback on grammar is frequently provided when writing and speaking, which demonstrates the importance that these teachers assign to this type of feedback, in line with the findings of other studies (Lee, 2003, 2008; Schulz, 2001). However, in language assessment circles, it is now widely predicted that interactional competence will become the 'fifth skill' (Walsh, 2012, p. 6). That is why, we believe that teachers need to gain a clear understanding of what classroom interactional competence is and how it can be developed, and to ensure that they provide their learners with grounded information on interactional subskills through feedback. 


\section{Conclusion}

Feedback pervades the school day: most interactions between teachers and students involve some element of feedback. That is why, we believe it is necessary to gain an insight into current FL assessment practices in primary education across Europe with regard to feedback, to help address them pedagogically and academically and contribute to teaching effectiveness.

In this study, we have shown that comparable feedback practices can be registered in dissimilar settings (the different skills are addressed in a similar fashion and with parallel acuteness) and that there are common areas for improvement across countries (such as the lack of emphasis on pronunciation and discourse-based feedback). Still, good practices and weaknesses can be identified and explained by taking into account the educational and social context (the emphasis on providing feedback on receptive skills in Spain and on writing in Slovenia can be interpreted in terms of local policies; Lešnik, Brumen \& Ivanuš-Grmek, 2013). More research is required to determine the influence of these contexts on the most appropriate way to deliver feedback on the different skills.

We acknowledge that the number of questionnaires gathered is limited and hence they reveal trends and not generalizations. Another caveat of this study is that the participants were asked to report on their beliefs about their feedback behaviour and it does not reflect their actual classroom performance. Thus, further research will involve enlarging our sample and contrasting the data with performance-based data, collected, e.g., through classroom observations and recordings of scripts from constructive feedback, which will reveal the nature and characteristics of feedback. In spite of these limitations, we believe that the outcomes obtained here are a relevant contribution within the context of teaching practice and recent literature on FL assessment and feedback.

\section{References}

Adams, M.J., Foorman, B.R., Lundberg, I., \& Beeler, T. (1998). Phonemic awareness in young children: A classroom curriculum. Baltimore, MA: Brookes Publishing.

Bitchener, J., Young, S., \& Cameron, D. (2005). The Effect of Different Types of Corrective Feedback on ESL Student Writing. Journal of Second Language Writing, 14, 191-205.

Celce-Murcia, M., \& Olshtain, E. (2000). Discourse and context in language teaching: A guide for language teachers. Cambridge: Cambridge University Press.

Derwing, T.M., \& Munro, M.J. (2005). Second language accent and pronunciation teaching: A research based approach. Tesol Quarterly, 39(3), 379-397.

Farrokhi, F. (2012). The Effects of Direct Written Corrective Feedback on Improvement of 
Grammatical Accuracy of High- proficient L2 Learners. World Journal of Education, 2(2), 49-57.

Ferris, D.R. (2002). Treatment of error in second language student writing. Ann Arbor: University of Michigan Press.

Fraenkel, J., Wallen, N. \& Hyun, H. (2014). How to Design and Evaluate Research in Education. New York: McGraw-Hill.

Hyland, K. \& Hyland, F. (2006). Contexts and issues in feedback on L2 writing: An introduction. In K. Hyland \& F. Hyland (Eds.), Feedback in second language writing: Contexts and issues, (pp. 1-19). Cambridge: Cambridge University Press.

Jang, E.E., \& Wagner, M. (2014). Diagnostic feedback in language classroom. In A. Kunnan (Ed.), Companion to language assessment, Vol. II (pp.693-711). Wiley-Blackwell.

Khatri, R. (2013). Feedback, student collaboration, and teacher support in English as a foreign language writing. IJSR - International Journal of Scientific Research, 2(2), 70-75.

Lee, I. (2003). L2 writing teachers' perspectives, practices and problems regarding error feedback. Assessing Writing, 8(3), 216-237.

Lee, I. (2008). Understanding teachers' written feedback practices in Hong Kong secondary classrooms. Journal of Second Language Writing, 17(2), 69-85.

Lešnik, S., Brumen, M. \& Ivanuš-Grmek, M. (2013). Attitudes of parents toward learning foreign languages: a Slovene case study. The New Educational Review, 34 (4), 52-62.

McKay, P. (2006). Assessing Young Language Learners. Cambridge: Cambridge University Press.

National examination centre. (2016). Retrieved 25/04/2018, from http://www.ric.si/preverjanje_znanja/statisticni_podatki/

Pardo, D.B. (2004). Can pronunciation be taught? A review of research and implications for teaching. Revisita Alicantina de Estudios Ingleses, 17, 6-38.

Schulz, R.A. (2001). Cultural Differences in Student and Teacher Perceptions concerning the Role of Grammar Instruction and Corrective Feedback: USA-Colombia. The Modern Language Journal, 85(2), 244-258.

Seedhouse, P. (2001). The case of the missing "no": The relationship between pedagogy and interaction. Language Learning, 51(Supplement 1), 347-385.

Sert, O. (2015). Classroom interaction and L2 Classroom Discourse. Edinburgh, University of Edinburgh.

Stobart, G. (2006). The validity of formative assessment. In J. Gardner (Ed.), Assessment and Learning (pp. 133-146). London: Sage.

Swain, M. (1995). Three functions of output in second language learning. In G. Cook \& B. Seidlhofer (Eds.), Principles and practice in applied linguistics: Studies in honour of H.G. Widdowson (pp. 125-144). New York: Oxford University Press.

Ur, P. (1996). A course in language teaching: Practice and theory. Cambridge: Cambridge University Press.

Walsh, S. (2011). Exploring Classroom Discourse: Language in Action. London: Routledge. Walsh, S. (2012). Conceptualising classroom interactional competence. Novitas-ROYAL (Research on Youth and Language) 6(1). 1-14. Retrieved 26/04/2018 from http://www. novitasroyal.org/Vol_6_1/Walsh.pdf 